\title{
Widen the big tent for big data: Understanding business student perceptions of Tableau
}

\author{
Heidi L. Dent, Western Carolina University,hdent@email.wcu.edu \\ Barbara Jo White, Western Carolina University,whiteb@email.wcu.edu \\ William A. Kapakos, Western Carolina University,wakapakos@email.wcu.edu \\ H. Kevin Fulk, Western Carolina University,hfulk@email.wcu.edu
}

\begin{abstract}
Business majors will encounter big data, and many will use data visualization tools to gain valuable insights and make strategic business decisions. However, core information systems classes for all business majors focus on improving information literacy but rarely include exercises with data visualization tools like Tableau. This study seeks to understand the perceptions business students have of Tableau after using it for several activities during a semester-long core business class. Specifically, the study examines the effects of gender, age, and major to understand how each factor affects student perceptions of Tableau including how easy it is to use, its value in the workplace, and how it compares to Excel. Tableau appealed to females just as much as males and to older students just as much as younger students. Tableau engaged with some majors more than others and appealed to CIS, Finance and Entrepreneurship majors more so than Marketing and Management majors (which include Management, Sport Management, Hospitality and Tourism, and Business Law). All majors saw the value of Tableau in workplaces for their future careers. Complete Tableau lab assignments available upon request.
\end{abstract}

Keywords: Tableau, Big Data, Data Visualization, Information Literacy, Excel

\section{Introduction}

Visual communication design is a necessary component across disciplines in preparation for industry applications. Educational planning for visual communication design endeavors to mirror rapidly developing technology while also evolving to accommodate multidisciplinary work (Dur, 2014). Research suggests that individuals are challenged with identifying and understanding data visualizations. Yet, improving the level of data visualization literacy should be a priority for academic institutions.

Frequently, experts in industry and higher education are calling for college students to have opportunities to graduate with valuable data visualization skills (Ryan, et al., 2019). Colleges and universities are attempting to answer this call for data visualization learning opportunities in various forms. Opportunities to learn data visualization skills can take the form of dedicated courses (Usova and Laws, 2021), components of existing courses (Kapakos, et al., 2020), and certification programs (Schuetz et al., 2020). Data visualization offerings are starting to be found in a variety of programs, such as science, technology, engineering, and mathematics (STEM) fields (Ryan, et al., 2019), social sciences (Henshaw and Meinke, 2018), and the focus of this study - business fields (Andiola, et al., 2020). Often, a sought-after outcome for these learning opportunities is data visualization literacy. 


\section{Issues in Information Systems}

Volume 22, Issue 4, pp. 51-62, 2021

Data visualization literacy (DVL) is defined as the "the ability to confidently use a given data visualization to translate questions specified in the data domain into visual queries in the visual domain, as well as interpreting visual patterns in the visual domain as properties in the data domain" (Boy et al, 2014). Data visualization literacy can be construed as a component of digital literacy and digital literacy a component of information literacy. Information literacy is cross-disciplinary, the need extending beyond information systems or computer science to meet the demands of industry post-graduation. While the importance of digital visualization literacy is commonly accepted, there is less agreement on how to effectively teach data visualization. Frameworks have been suggested in order to create a more cohesive "typology, process model, and exercises for defining, teaching, and assessing DVL" (Börner et al., 2019).

Information literacy is the competence of users to determine when information is needed and then locate, evaluate, and apply that information. Visualization literacy, with data visualization, falls under the broader umbrella of information literacy, which often involves technology. Today's students typically enter college with previous experience and exposure to technology which influences how they learn and their interest in learning computer and information technology in the classroom (Ciampa, 2013).

This paper presents a multidisciplinary study of student responses to data visualization activities using Tableau in a core undergraduate business information systems class. Specifically, the study examines how age, gender, and major affect student perceptions of Tableau compared to Excel, their perceptions of Tableau in the workplace and their perceptions of Tableau activities.

\section{Background}

\section{Major and Information Literacy}

Research shows there are differences relating to information technology and technology usage among business majors. For example, research indicates that some majors believe their knowledge to be superior to others in evaluating different forms of messages, the quality and credibility of the content, and their ability to utilize search and create multimedia (O'Callaghan et.al., 2021). Students, dependent upon major, have established a hierarchy of their perceptions of their digital literacy skills, with Accounting majors feeling superior to Finance majors and CIS majors feeling superior to Accounting majors (O'Callaghan et.al., 2021).

More recently established majors such as Entrepreneurship have also embraced the value of information literacy. This is evidenced by an increasing textbook coverage of IT topics such as IT management, computer literacy, e-commerce and the Internet, as well as office productivity software (Davidson et al., 2012).

Early studies of student appraisal and use of various office productivity applications also show differences between business majors. Bartholomew and colleagues (2003) showed business management majors reporting lower appraisal scores than IS or Accounting majors. Finance majors, Accounting majors and CIS majors all reported using office productivity applications (such as Word and Excel) more than business management or marketing majors (Bartholomew et al, 2003). Beyond office productivity software applications, other software, such as data visualization software may also show differences due to major but few, if any, studies have been conducted. Data visualization typically has been targeted to majors in information systems in classes at the graduate level or at the undergraduate level. Rarely and only recently have data visualization activities been used with students in other disciplines in undergraduate courses (Andiola, et al., 2020; Kapakos, et al., 2020). 


\section{Issues in Information Systems}

Volume 22, Issue 4, pp. 51-62, 2021

\section{Age and Information Literacy}

Age has been studied in a variety of digital literacy and technology-related studies using various methods examined for enhancing the learning of technology in the classroom. For example, using a visual gamification application that used integrated software in classroom learning environments, Ashtari and Taylor (2021) studied age and how it interacts with gamification. They found that age functions as a moderator of the relationship between ability and motivation and the perception of learning (Ashtari and Taylor, 2021).

Regarding age and computers and technology, research is mixed. For example, some research shows age differences with younger students having higher ratings than older students in technology and digital literacy studies. O'Callaghan and colleagues (2021) studied age and digital literacy with results showing that age impacted two of the measures of digital literacy. Specifically, younger students $(<25$ years of age $)$ had higher self-ratings of their abilities to connect with others online and use communication as a tool for advocacy compared to older students. Also, Ciampa's research (2013) shows a positive and significant correlation between age and the importance connecting to the Internet with the younger generation feeling that connecting to the Internet was more important than the older generation. Furthermore, younger students were more likely to obtain certification for learning acquired in a technology-related online course compared to older students (Arslan, et al., 2015). However, not all research shows differences between the ages. Ciampa (2013) shows that there is no significant difference between older individuals and the younger individuals with respect to perceptions of importance of various computer administrative tasks such as verifying information, word processing, and using different functions.

\section{Gender and Information Literacy}

Gender is often a consideration in technology-related studies. As academics develop frameworks and adjust their pedagogical approaches, consideration needs to be given to student demographics. The communication of data through visual means such as infographics and data visualization can benefit students with their research, studies, analytical thinking, design approach to solution methods and teamwork (Dur, 2014). Different learners, however, engage with different narrative and visual arguments through social and pluralistic processes for deriving meaning from data and visualization (D'Ignazio and Bhargava, 2020).

Regarding gender and software or computer tasks, although media often reports males have better performance with technology, results are mixed. When it comes to acceptance of new technologies, research suggests that with email, information retrieval, e-learning, communication technologies and online purchasing behavior, males were more accepting of new technologies compared to females (Orji, 2010). Women tend to have more anxiety over technology, ease of use, expectations of effort for return and experienced more difficulties than males with e-learning technologies (Goswami and Dutta, 2016), as well as have lower self-efficacy and less stereotypic computer attitudes (Jackson et al, 2001). On the other hand, researchers have found that the use of information technology is contradictory based on gender (He and Freeman, 2010). Males do not necessarily see all computer tasks as equally relevant. Also, females typically deem various computer administrative tasks (such as verifying information, creating a table (word processing), and using functions) as more important compared to males (Ciampa, 2013).

\section{Methodology}

A survey was administered to 12 sections of a core business class in information systems taught in the Fall of 2020 ( 9 sections) and the Spring of 2021 (3 sections). Due to the pandemic, there were many distance sections (5) while the remaining sections were "hybrid" with part face-to-face and part distance attendance. 


\section{Issues in Information Systems}

Volume 22, Issue 4, pp. 51-62, 2021

Typically, attendance on campus was $10 \%$ of the expected amount making the hybrid sections mostly taught like distance sections too. All sections used the same course shell with instructional videos showing students how to use Tableau. These instructional videos included a corresponding PowerPoint file that students could follow along with that provided information about the user interface and terminology of Tableau, sorting data by ascending and descending values, changing color palettes, interpreting sales data, etc. Recorded video solutions were made available for students as well.

Tableau was introduced midway through the semester, after students were exposed to working with Excel. In an effort to maintain consistency between assignments that focused on different software, Tableau activities followed a similar format to the Excel assignments. In total, there were four Tableau activities: two labs and two practice labs that preceded each lab. The first practice lab and lab dealt with bar charts. In these labs students were tasked with creating stacked bar charts showing total amounts broken down into sub-amounts where parts of the data are stacked, in addition to comparing multiple sets of data with grouped bar charts. The second practice lab and lab dealt primarily with line charts. Students leveraged what they learned in the prior labs and built upon their skills by focusing on creating grouped and multi-line charts, adding trend lines and other line chart attributes. Each assignment had a lab component asking students to create two to six charts using a large data set that is included with Tableau. In all cases, students were shown images of the solution charts, so they knew where they were headed. Following the lab components, a set of quiz questions asked students to alter their charts according to a prompt and then choose a multiplechoice answer in response.

\section{Results}

A summary of Tableau lab questions is available in Appendix B and Appendix C. The results of student performance on the Tableau activities are below (Figure 1):

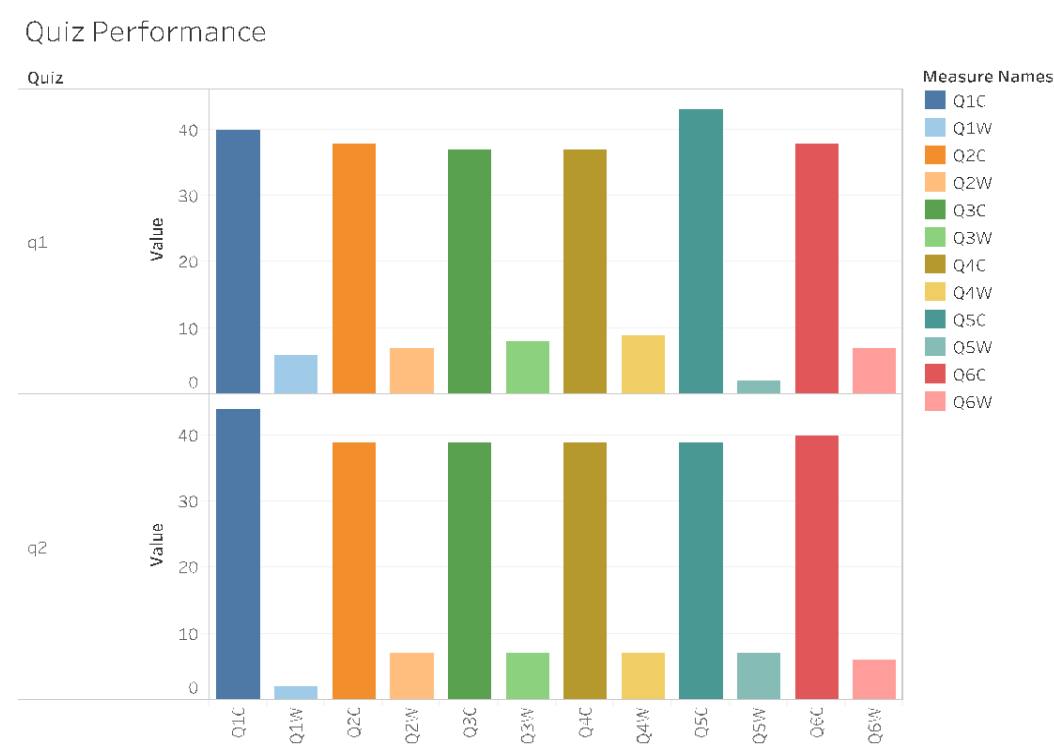

Figure 1: Measure Names include quiz questions correct and wrong. Data is broken out by quiz 1 (q1) and quiz 2 (q2)

A total of 304 students completed the survey, with approximately equal numbers of male (48.4\%) and female $(51.6 \%)$ respondents, although most of them were 34 or younger $(84.9 \%)$. Most of the female 


\section{Issues in Information Systems}

Volume 22, Issue 4, pp. 51-62, 2021

respondents were in the management area working on a business law degree taught through a distance program.

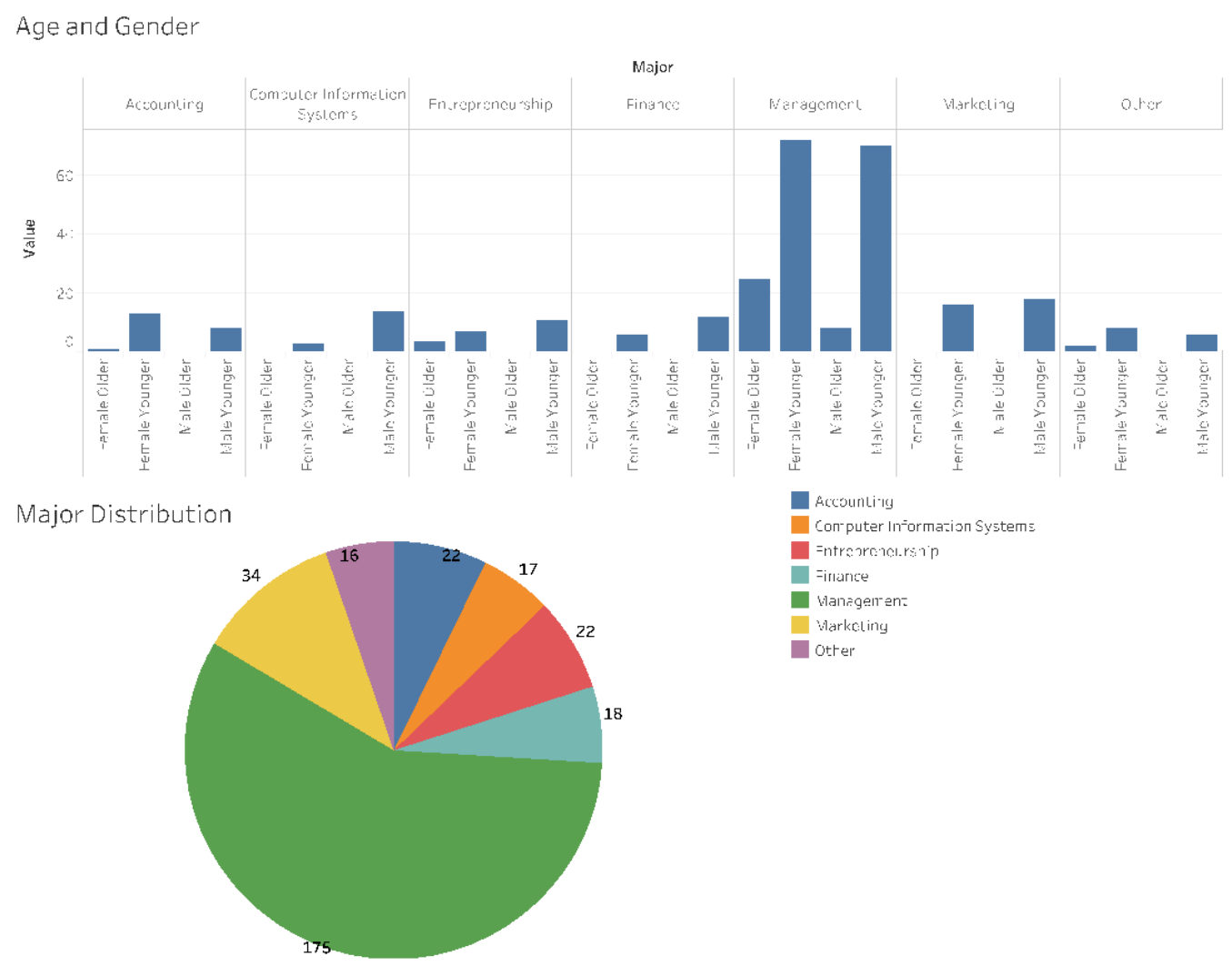

Figure 2: Tableau Visualization of Demographic data by age, gender and major

Most of the surveys (79.3\%) were completed immediately after the students finished the second Tableau lab while a smaller group of students $(20.7 \%)$ completed surveys approximately 5 weeks later. An independent samples T-test showed no difference between respondents who completed the survey immediately after $(M=33.35, S D=7.77)$ or five weeks after $(M=33.02, S D=7.72)$ taking the Tableau lab and their perceptions as a whole. There were also no significant differences regarding Tableau's ease of use between respondents who completed the survey immediately after $(M=15.04, S D=4.12)$ or five weeks after $(M=14.94, S D=3.95)$ completing the Tableau lab; Tableau's workplace value between respondents who completed the survey immediately after $(M=11.46, S D=2.48)$ or five weeks after $(M=$ 11.54, $S D=2.65$ ) completing the Tableau lab; or how Tableau compared to Excel between respondents who completed the survey immediately after $(M=10.18, S D=3.28)$ or five weeks after $(M=9.54, S D=$ 3.05) taking the Tableau lab.

One-sample T-tests showed that, overall, students had very positive perceptions about Tableau $(M=33.28$, $S D=7.75), t(303)=7.29, p<.000)$, that students valued Tableau in the workplace and in their disciplines $(M=11.48, S D=2.51), t(303)=17.23, p<.000)$, that Tableau appealed to students more than Excel $(M=$ $10.05, S D=3.24), t(303)=5.65, p<.000)$, and that students found Tableau easy to use $(M=15.02, S D=$ $4.07), t(303)=12.93, p<.000)$.

An independent samples T-test showed no difference between males $(M=32.73, S D=7.80)$ and females $(M=33.80, S D=7.69)$ and their perceptions of Tableau as a whole, or its ease of use between males $(M=$ $14.79, S D=4.07)$ and females $(M=15.23, S D=4.07)$, workplace value between males $(M=11.42, S D=$ 


\section{Issues in Information Systems}

Volume 22, Issue 4, pp. 51-62, 2021

2.59) and females $(M=11.54, S D=2.44)$, or how Tableau compared to Excel between males $(M=9.80$, $S D=3.14)$ and females $(M=10.28, S D=3.32)$. While there were no significant differences, in all cases, females scored higher than males.

An independent samples T-test showed no difference between younger $(M=33.15, S D=7.85)$ and older $(M=34.15, S D=7.08)$ respondents and their perceptions of Tableau as a whole, or its ease of use between younger $(M=14.95, S D=4.15)$ and older $(M=15.45, S D=3.47)$ respondents, workplace value between younger $(M=11.42, S D=2.51)$ and older $(M=11.88, S D=2.49)$ respondents, or how Tableau compared to Excel between younger $(M=10.02, S D=3.27)$ and older $(M=10.28, S D=3.09)$ respondents. While there were no significant differences, in all cases, older respondents scored higher than younger students.

A one-way ANOVA showed that, overall, perceptions of Tableau differed depending on student majors $[F(6,297)=3.30, p=.004]$, which were grouped into CIS, Finance, Accounting, Entrepreneurship, Marketing, and the Management group (which included Management, Business Law, Sport Management, and Hospitality and Tourism). Specifically, CIS students differed significantly from Marketing students ( $M$ $=6.71, S D=2.25)$ and from the group of Management students $(M=6.07, S D=1.93)$. In terms of ease of use $[F(6,297)=3.96, p=.001]$, Finance students differed significantly from Marketing students $(M=$ $3.83, S D=1.15)$ and the Management group $(M=3.45, S D=0.98)$.

\section{Discussion}

This study's objective was to understand the value of adding opportunities to learn an industry-leading data visualization tool to an existing CIS course taken by business students as part of their degree requirements. In this way, this study differed from research that has examined students' behavioral intentions to use technologies in voluntary use settings with the Technology Acceptance Model (Davis, 1989). It is heartening to know that students, regardless of gender, age or major, believe that Tableau is useful in their future workplaces, that it is easy for them to use, and that they like it more than Excel. Though all majors have positive feelings about Tableau, some majors have stronger positive feelings compared to other majors. For example, CIS, Accounting, Finance, and Entrepreneurship majors all had stronger positive feelings about Tableau compared to Management and Marketing majors. The fact that there are no significant differences between males and females and younger and older students when it comes to perceptions of Tableau offers a very optimistic view in closing the age and gender gaps.

As with all research, the current study has multiple limitations. First, it is possible that students preferred Tableau to Excel simply because Tableau was a novel, new technology to them and people are generally drawn to what is novel or unique (Brown and White, 2009). Another potential limitation might have been due to the timing of the labs. The Excel lab that directly preceded the Tableau labs did not have the answers visible (only the first two Excel labs did) which might have increased the difficulty of Excel in the minds of students. In addition, due to losing access as part of converting from one learning management system to another, some student Tableau assignment scores were not accessible. Lastly, the timing of this study during the ongoing pandemic means that readers should interpret findings with care.

As faculty progress with constructing pedagogy to address data visualization and information literacy, Tableau proves to be an application that supports more inclusive environments in the classroom. This is a useful implication for faculty members who are considering including data visualization in similar courses to the core information systems course used in this study. In addition, the value that students taking part in this study found in using Tableau should be encouraging to other students who may question the merits of taking a course that includes learning data visualization skills. 


\section{Issues in Information Systems}

Volume 22, Issue 4, pp. 51-62, 2021

\section{References}

Andiola, L. M., Masters, E., \& Norman, C. (2020). Integrating technology and data analytic skills into the accounting curriculum: Accounting department leaders' experiences and insights. Journal of Accounting Education, 50, 1-18.

Arslan, F., Bagchi, K., \& Ryu, S. (2015). A preliminary evaluation of the determinants of certification success in MOOCs: A multi-level study. Proceedings of the Twenty-First Americas Conference on Information Systems, Puerto Rico, 21, 1-13.

Ashtari, S., \& Taylor, J. (2021). Winning Together: Using game-based response systems to boost perception of learning. International Journal of Education and Development using Information and Communication Technology, 21(1), 123-141.

Bartholomew, K. W., Johnson, D. W., Ormond, P. R., \& Mulbery, K. R. (2003). Computer literacy: Use IT or lose it! The Journal of Business Inquiry, 1(2), 6-14.

Börner, K., Bueckle, A., \& Ginda, M. (2019). Data visualization literacy: Definitions, conceptual frameworks, exercises, and assessments. Proceedings of the National Academy of Sciences, USA, $116(6), 1857-1864$.

Boy J., Rensink R.A., Bertini E., \& Fekete J-D. (2014) A principled way of assessing visualization literacy. IEEE Transactions on Visualization and Computer Graphics, 20(12), 1963-1972.

Brown, J. A. E., \& White, B. J. (2009). Modeling desired behaviors: Do leaders need new technology? Leadership \& Organization Development Journal, 30(2), 124-138.

Ciampa, M. (2013). Student perceived importance and correlations of selected computer literacy course topics. Journal of Instructional Pedagogies, 11, 1-17.

Davidson, B., White, B. J., \& Taylor, M. (2012). The rise of IT for entrepreneurs and the increasing entrepreneurial focus for IT professionals. Issues in Information Systems, 13(2), 104-111.

D'Ignazio, C., \& Bhargava, R. (2020). Data visualization literacy: A feminist starting point. In M. Engebretsen, \& H. Kennedy (Eds.), Data visualization in society (pp. 207-222). Amsterdam University Press.

Dur, B.I. (2014). Data visualization and infographics in visual communication design education at the age of information. Journal of Arts and Humanities, 3(5), 39-50.

Goswami, A., \& Dutta, S. (2015). Gender differences in technology usage-A literature review. Open Journal of Business and Management, 4(1), 51-59.

He, J., \& Freeman, L. A. (2010). Are men more technology-oriented than women? The role of gender on the development of general computer self-efficacy of college students. Journal of Information Systems Education, 21(2), 203-212.

Henshaw, A. L., \& Meinke, S. R. (2018). Data analysis and data visualization as active learning in political science. Journal of Political Science Education, 14(4), 423-439. 


\section{Issues in Information Systems}

Volume 22, Issue 4, pp. 51-62, 2021

Kapakos, W. A., White, B. J., Clapper, D. L., \& Willey, L. (2020). Emerging technology: Introducing Tableau to CIS and non-CIS majors in a core business class. Issues in Information Systems, 21(3), $31-40$.

Jackson, L.A., Ervin, K.S., Gardner, P.D., \& Schmitt, N. (2001). Gender and the internet: Women communicating and men searching. Sex Roles, 44, 363-379.

O'Callaghan, S., Calloway, L. J., Walker, J. P., Elson, R. J., Dwyer, C., Boumediene, S., \& Boumediene, S. (2021). Digital literacy and accounting students: Implications for the profession. Global Journal of Accounting and Finance, 5(1), 45-63.

Orji, R. (2010). Impact of gender and nationality on acceptance of a digital library: An empirical validation of nationality based UTAUT using SEM. Journal of Emerging Trends in Computing and Information Sciences, 1(2), 68-79.

Ryan, L., Silver, D., Laramee, R. S., \& Ebert, D. (2019). Teaching data visualization as a skill. IEEE Computer Graphics and Applications, 39(2), 95-103.

Schuetz, C., Been, J., \& Chan-Park, C. Y. (2020). Here and hereafter: Preparing business students for a data-driven world. Journal of Business \& Finance Librarianship, 25(3-4), 1-23.

Usova, T., \& Laws, R. (2021). Teaching a one-credit course on data literacy and data visualization. Journal of Information Literacy, 15(1), 84-95.

\section{Appendix A: Survey Items}

In addition to recording whether there was a lapse between students taking the survey after the activity or not, the survey asked demographic questions regarding age, gender, and major. The following items were also included (see Table 2 below):

Table 2. Survey Items

(5-point Likert Scale: $1=$ Strongly Disagree; 5=Strongly Agree)

\section{Tableau and Excel Survey Items}

1. I feel more successful with Tableau than Excel

2. I liked Tableau more than Excel

3. It takes longer to learn Tableau than Excel (Reverse Coded)

\section{Workplace Value of Tableau Survey Items}

1. Tableau is useful in the workplace

2. Knowing something about Tableau can help me find a job in my discipline.

3. Majors in my discipline would benefit from knowing Tableau

The Use of Tableau Survey Items

1. Learning to use Tableau was easy for me

2. I find it easy to use Tableau

3. My interaction with Tableau was clear and understandable

4. It would be easy for me to become skillful using Tableau 


\section{Appendix B: Data from Tableau Lab Quiz 1: Bar Charts}

\begin{tabular}{|c|c|c|c|}
\hline Question & Question Results & $\begin{array}{l}\text { Typical Student } \\
\text { Error Image } \\
\end{array}$ & Image Provided \\
\hline $\begin{array}{l}\text { 1. Create a horizontal bar chart to show sales by } \\
\text { sub-category (with sub-category on the vertical } \\
\text { axis). Title the chart so that it reads: Sheet } 1 \text { : Last } \\
\text { Name, FirstName: Sales by Sub-category ( } 2016 \\
\text { to Present). Fit chart to entire view. Change the } \\
\text { bar colors to red and display labels for sales. }\end{array}$ & 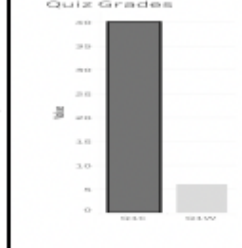 & & 春 \\
\hline $\begin{array}{l}\text { 2. Create a stacked bar chart to show sales by } \\
\text { region, and within region by ship mode (with } \\
\text { sales on the vertical axis). Title the chart so that it } \\
\text { reads: Sheet } 2 \text { : Last Name, FirstName: Sales by } \\
\text { Ship Mode and Region ( } 2016 \text { to Present). Fit } \\
\text { chart to entire view. Apply the color-blind palette } \\
\text { and display the labels for sales. }\end{array}$ & 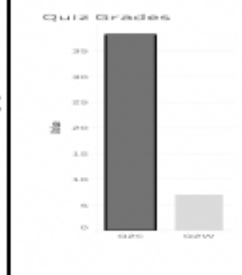 & - & \\
\hline $\begin{array}{l}\text { 3. Create a grouped bar chart to show the quantity } \\
\text { of units by segment, and within segment by ship } \\
\text { mode (with quantity on the vertical axis). Title } \\
\text { the chart so that it reads: Sheet } 3 \text { : Last Name, } \\
\text { FirstName: Quantity of Units by Segment and } \\
\text { Ship Mode ( } 2016 \text { to Present). Fit chart to entire } \\
\text { view. Change the bar colors to blue, orange and } \\
\text { red for the consumer, corporate and home office } \\
\text { segments, respectively. Display the labels for } \\
\text { units in thousands with no decimals. } \\
\end{array}$ & 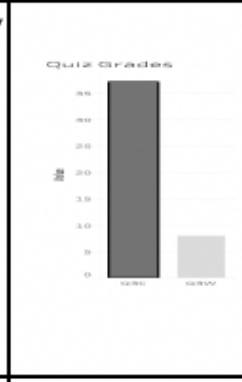 & & \\
\hline $\begin{array}{l}\text { 4. Create a grouped bar chart to show the quantity } \\
\text { of units by segment and state (show NC only and } \\
\text { show quantity on the vertical axis). Title the chart } \\
\text { so that it reads: Sheet } 4 \text { : Last Name, FirstName: } \\
\text { Quantity of Units by Segment and State (NC) } \\
\text { (2016 to Present). Fit chart to entire view. } \\
\text { Change the bar colors to blue, orange and red for } \\
\text { the consumer, corporate and home office } \\
\text { segments, respectively. Display the labels for } \\
\text { units with no decimals. }\end{array}$ & 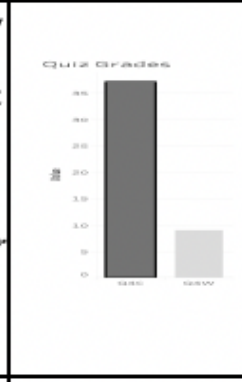 & 点 & \\
\hline $\begin{array}{l}\text { 5. Create a horizontal bar chart to show the top } 10 \\
\text { states that have the largest discount (with the } \\
\text { states on the vertical axis). Title the chart so that } \\
\text { it reads: Sheet } 5 \text { : Last Name, FirstName: Top Ten } \\
\text { States with the Largest Discounts ( } 2016 \text { to } \\
\text { Present). Fit chart to entire view. Display the } \\
\text { labels for discount and drag the discount pill over } \\
\text { the colors card to create a color scale. Sort } \\
\text { descending. }\end{array}$ & 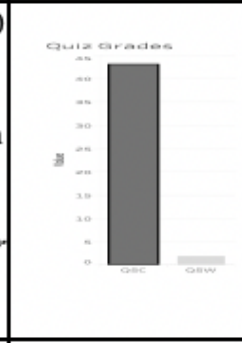 & & (40) \\
\hline $\begin{array}{l}\text { 6. Create a grouped bar chart to show profit for } \\
\text { each segment by ship mode, and within ship } \\
\text { mode, the region. Show ship mode by region on } \\
\text { the vertical axis and profit by segment on the } \\
\text { horizontal axis. Title the chart so that it reads: } \\
\text { Sheet } 6 \text { : Last Name, FirstName: Profit for } \\
\text { Segments by Ship Mode and Region ( } 2016 \text { to }\end{array}$ & 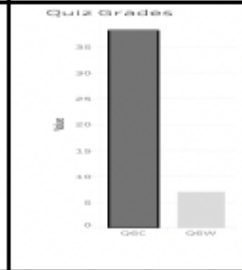 & {$\left[\begin{array}{l}- \\
- \\
- \\
- \\
-\end{array}\right.$} & 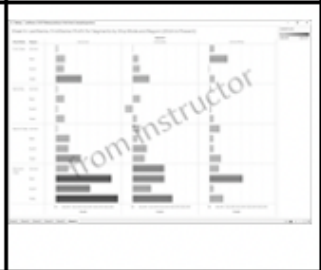 \\
\hline
\end{tabular}

Figure 3: Quiz 1 Questions, Results, Typical Error and Image Provided 


\section{Appendix C: Data from Tableau Lab Quiz 2: Line Charts}

\begin{tabular}{|c|c|c|c|}
\hline Original Tableau Lab Question & $\begin{array}{c}\text { Quiz Question } \\
\text { Results }\end{array}$ & $\begin{array}{l}\text { Typical Student } \\
\text { Error Image }\end{array}$ & $\begin{array}{l}\text { Answer Image } \\
\text { Provided }\end{array}$ \\
\hline $\begin{array}{l}\text { 1. Create a line chart to show quarterly sales } \\
\text { over time (with sales on the vertical axis). Title } \\
\text { the chart so that it reads: Sheet } 1 \text { : Last Name, } \\
\text { FirstName: Quarterly Sales Over Time. Fit } \\
\text { chart to entire view. Change the line color to } \\
\text { green, add markers and display the labels for } \\
\text { sales. }\end{array}$ & 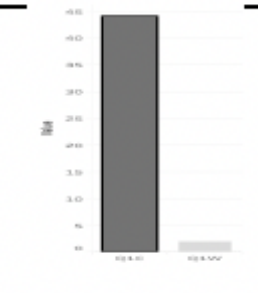 & & \\
\hline $\begin{array}{l}\text { 2. Create a multi-line chart to show quarterly } \\
\text { sales in the south and central regions (with } \\
\text { sales on the vertical axis). Title the chart so that } \\
\text { it reads: Sheet 2: Last Name, FirstName: } \\
\text { Quarterly Sales by Region. Fit chart to entire } \\
\text { view. Add a linear trend line and increase the } \\
\text { size of the lines to half thickness }\end{array}$ & 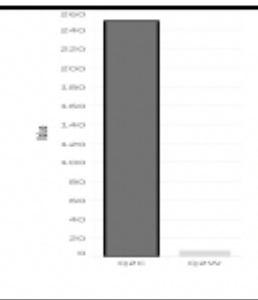 & $\begin{array}{l}\bar{z} \\
= \\
\bar{z} \\
\bar{z}\end{array}$ & \\
\hline $\begin{array}{l}\text { 3. Create a line chart to show the quantity of } \\
\text { units for each month by region in } 2018 \text { (with } \\
\text { region by quantity on the vertical axis). Title } \\
\text { the chart so that it reads: Sheet } 3 \text { : Last Name, } \\
\text { FirstName: Monthly Number of Products Sold } \\
\text { by Region in } 2018 \text {. Fit chart to entire view. } \\
\text { Add a linear trend line, markers and display } \\
\text { the labels for quantity of units. }\end{array}$ & 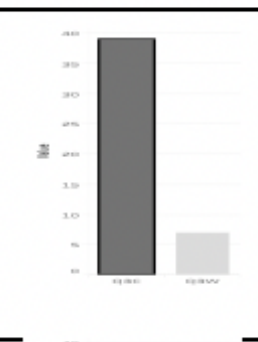 & & \\
\hline $\begin{array}{l}\text { 4. Create a multi-line chart to show the } \\
\text { monthly profit ratio for the consumer and } \\
\text { corporate segments (with profit ratio on the } \\
\text { vertical axis). Title the chart so that it reads: } \\
\text { Sheet } 4 \text { : Last Name, FirstName: Monthly Profit } \\
\text { Ratio by Segment. Fit chart to entire view. Add } \\
\text { markers and display the profit ratio labels. }\end{array}$ & 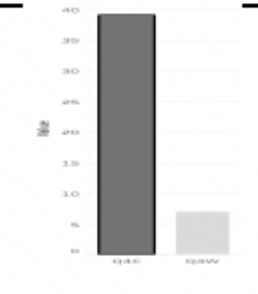 & $\begin{array}{l}= \\
=\end{array}$ & \\
\hline $\begin{array}{l}\text { 5.Create a line chart to show the sum of sales } \\
\text { and the sum of profit for each month. Title the } \\
\text { chart so that it reads: Sheet } 5 \text { : Last Name, } \\
\text { FirstName: Monthly Sales and Profit in a } \\
\text { Single Axis. Fit chart to entire view. To } \\
\text { compare two measures into a single axis, drag } \\
\text { the profit pill from the rows shelf to the sales } \\
\text { axis. }\end{array}$ & " & & \\
\hline $\begin{array}{l}\text { 6. Create a line chart to show the monthly } \\
\text { discount for central and west regions in } 2018 \\
\text { (with discount on the vertical axis). Title the } \\
\text { chart so that it reads: Sheet } 6 \text { : Last Name, } \\
\text { FirstName: Monthly Discount for Central and } \\
\text { West Regions in } 2018 \text {. Fit chart to entire view. } \\
\text { Add a trend line and display the labels for the } \\
\text { discount. }\end{array}$ & 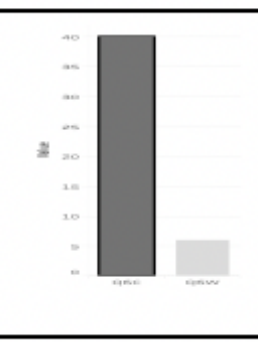 & " 3 & \\
\hline
\end{tabular}

Figure 4: Quiz 2 Questions, Results, Typical Error and Image Provided 